\section{Those babies still pose problems}

by Miranda Robertson

IT has not been entirely clear from press reports over the past two weeks that no child in the immediately foresceable future is likely to have been in any sense a test tube baby. The most that is contemplated is the occasional emergence-in the traditional manner, from a woman-of a baby which spent its first few days as a fertilised ovum in a Petri dish (test tubes are not used for this kind of thing). That much is in principle quite possible and even desirable, although there are good reasons for supposing, in spite of claims at the recent British Medical Association meeting in Hull, that it may not yet have happened.

Scepticism about Professor Bevis's announcement could only be abolished by the publication of a technique which proved more successful than those already reported. The existence of three children, even if they were born to couples who had taken part in artificial inovulation trials, cannot vindicate the claim: where the wife is the egg donor and the husband the sperm donor, there is no way of telling whether the baby developed from the reimplanted egg, or whether it was naturally conceived in the course of the experiment, as can sometimes happen with presumed infertile couples.

The transfer of eggs fertilised outside the body into the uterus to complete development is already routine in laboratory animals used in genetic and developmental research. It is somewhat trickier to get eggs from humans than it is from mice or rabbits, but even so the techniques for obtaining viable fertilised human ova, developed over the past few years in Britain by $\mathrm{Mr}$ Patrick Steptoe of the Oldham and District General Hospital, and Dr Robert G. Edwards, of the University of Cambridge, are now extremely reliable. The problems which have prevented the animal success from being extended to humans lie not within the embryo but with the reproductive physiology of the mother in whose uterus the embryo must be able to implant.

It is not particularly surprising that the fourteen egg transfers so far reported by $\mathrm{Mr}$ Steptoe have failed. Even in mice, the failure rate for implantation of transferred eggs is something like $50 \%$. There is every reason to suppose that some proportion of all fertilised eggs in normal women fail to implant and are flushed out, unnoticed, with the next menstual flow. Patients whose infertility is an indication for artificial inovulation are not normal women. The blocked oviducts which makes the procedure necessary are likely to be the consequence of disease which may have had other effects on the reproductive apparatus. The very procedure of injecting the fertilised ovum into the womb may initiate contractions which militate against implantation.

Finally, the hormonal interaction between the mother and the embryo is both critical and ill understood. In order to control the timing of reimplantation of the ovum, the woman's cycle is induced artificially with hormones, and this may result in endocrine deficiencies which could account for the failures. Nor is it clear what is the optional point at which reimplantation should be attempted.

Clearly, it is only a matter of time before someone produces a baby which began its life in laboratory glassware. That is a realistic and human goal according to Dr Edwards: "To give a couple their own child obviously needs no justification" and fears about the possible biological hazards and social implications of the technique seem on the whole unwarranted.

The misgivings voiced by the Medical Research Council on the abnormalities in embryos fertilised in vitro do not seem to be substantiated by the considerable body of data on animals (Nature, 244, 333; 1973). The essential point is that the embryo before implantation is undifferentiated and thus almost impervious to injury. If enough cells are killed during the manipulations, the embryo dies. If it does not die, the cells regulate to produce a normal organism. There is a slight danger of triploidy if the ovum is fertilised by more than one sperm, but this can be avoided by proper control of the number of sperm used to fertilise one egg.

Most of the social, legal and ethical issues raised in connection with fertilisation in vitro differ little from those which arise in connection with artificial insemination or with adoption. The more horrendous imaginings of determined doomwatchers can probably be dismissed under the general proposition that it does not follow that once a thing is feasible it will necessarily or even probably be turned to undesirable ends.

These arguments, both on the feasibility and on the desirability of the technology for growing embryos in vitro, apply only to preimplantation development. The human uterus is still irreplaceable between six days and 24 weeks of gestation, which includes the most critical developmental periodthat of differentation, when the foetus is at its most susceptible to teratogenic influences. Not only are the problems inherent in the creation of an artificial womb during this period enormous, but none of the stated aims of current research on human embryos in vitro would be served by it. The immediate aims as seen by Mr Steptoe are to overcome infertility in the $2 \%$ of couples in which it is caused by blocked oviducts, to control sex-linked disease by selecting fertilised eggs of one sex only for reimplantation, to investigate the causes of abnormality in preimplantation embyros, and to test male contraceptive drugs which can only be evaluated on the basis of their ability to prevent sperm from fertilising eggs. None of these goals would be advanced by the development at vast expense of an elaborate surrogate uterus. Not only does $\mathrm{Mr}$ Steptoe see no medical justification for carrying development in vitro further than the first few days, but the danger of abnormalities in the foctus does become serious once differentiation begins.

\section{Crisis in science education}

from Peter Lindon

AN unhappy conjunction of two events was the origin of a conference on The Crisis in Engineering and Science Education in the West held at The University of Manchester Institute of Science and Technology (UMIST) on July 16 and 17 . The two events in question were the 150th anniversary of the Institute and the decline in applications for science and engineering in the universities.

A sense of gloom and impending disaster was created from the beginning as Lord Bowden the Principal of UMIST predicted bankruptcy within 18 months for universities in the absence of any change in government policies. With student applications having dramatically fallen, and classes containing an ever increasing proportion of foreign students he wondered where the engineers and scientists to drive our essential industries would be coming from. The mechanism of manpower supply and demand seemed to be scriously at fault. From the time a child made decisions affecting the future direction of his studies until the time when he qualificd, some $8-10$ years had elapsed: a lag which must be an inherent cause of instability in recruitment to industry and enrolment at universities. It is precisely at the time when the need for scientists is greatest that the numbers and quality of science school teachers are eroded, the children become disillusioned with their experience of science in the schools, and the manpower supply is shut off.

Some contributors did not consider this mechanistic explanation sufficient. The social influences upon student choice were also important and Sir 